\title{
Life Cycle Impact Assessment of Polylactic Acid (PLA) Produced from Sugarcane in Thailand
}

\author{
Ana Morão ${ }^{1}$ (i) . François de $\mathrm{Bie}^{2}$
}

Published online: 22 August 2019

(c) The Author(s) 2019

\begin{abstract}
In this study we provide up-to-date cradle-to-gate information on the environmental footprint of polylactic acid (PLA) produced in Thailand at commercial scale, covering emerging topics such as water footprint and direct land use change. The enormous potential to further reduce the environmental impacts of PLA through improvements in feedstock production as well as in the PLA manufacturing process is also demonstrated. Life cycle assessment (LCA) is performed according to the ISO 14040/44 standard methodology. The 16 environmental impact categories from ILCD 2011 Midpoint + were considered for the hotspot analysis. As primary data actual industrial data were used for the sugar production, lactic acid production (Corbion) and PLA production (Total Corbion PLA), including various recently developed process insights. The agricultural feedstock production and the manufacturing process of PLA from sugar contributed most to the LCA impacts of PLA production. The sugarcane crop production particularly affected the environmental impact categories analyzed, including global warming potential (GWP), water, eutrophication, acidification, particulate matter and, inevitably, land use. However, when combined with the results of a sustainability risk assessment study, it becomes clear that land use and water-related impacts represent a low risk for the feedstock-sourcing area. The environmental impact categories of PLA manufacturing are mostly linked to energy and chemicals usage. Improvements in the environmental performance of PLA can be achieved through improvements in the sugarcane farming practices, higher efficiency bagasse boilers at the sugarmill, reduced usage of auxiliary chemicals and increased usage of renewable energy in the conversion process of sugar to PLA. From a cradleto-gate perspective, considering the uptake of carbon dioxide in the PLA molecule, the GWP is $501 \mathrm{~kg} \mathrm{CO}_{2}$ eq/ton PLA.
\end{abstract}

Keywords Biobased plastic $\cdot$ Polylactic acid (PLA) $\cdot$ Lactic acid $\cdot$ Life cycle assessment (LCA) $\cdot$ Luminy

\section{Introduction}

Biobased products are totally or partly derived from materials of biological origin, such as, crops, plants or other renewable agricultural, marine or forestry materials. These products, provide alternative material options to conventional petroleum-based materials by using renewable carbon as feedstock. Biobased products are a priority area for the EU because of their high potential for future growth and their sustainable nature facilitating the biobased economy [1].

Ana Morão

ana.morao@corbion.com

1 Corbion Global R\&D, P.O. Box 21, 4200 AA Gorinchem, The Netherlands

2 Total Corbion PLA, P.O. Box 21, 4200 AA Gorinchem, The Netherlands
The use of renewable carbon feedstocks for chemical production has a clear link to reducing the risk of climate change and reduced dependency on fossil resources: during the production of these materials atmospheric $\mathrm{CO}_{2}$ is absorbed by the plants [2]. This carbon is eventually released at the end of the product lifecycle, with a net neutral impact on the atmospheric $\mathrm{CO}_{2}$ concentration. Therefore, when compared to fossil-based counterparts, biobased chemicals avoid the use of additional fossil carbon resources as feedstock. According to McGlade and Akins, globally, a third of oil reserves, half of the gas reserves and over 80 percent of current coal reserves should remain unused from 2010 to 2050 in order to meet the target of $2{ }^{\circ} \mathrm{C}$ global warming, compared to pre-industrial levels [3]. However, it should be noted that the production of biobased materials also requires energy (e.g., for the manufacturing process and transport), which could and should be of renewable sources to further reduce the fossil fuel dependency. When fossil-based 
resources are transformed into products, at the end of their life cycle additional $\mathrm{CO}_{2}$ is released into the atmosphere, contributing to Global warming potential (GWP). The increasing market share of these products calls for a broader understanding of their implications at the economic, social and environmental level. The environmental performance these products are generally assessed by Life Cycle Assessment (LCA), a well established methodology that uses a holistic approach to identify trade-offs between impact categories and to avoid shifting burdens over the value chain.

Polylactic acid (PLA) is the most widely used commercial bio-based plastic with characteristics similar to polystyrene, polypropylene or polyethylene [4]. PLA has a growing range of applications depicting improved product functionalities over traditional polymers, for example reducing the printing temperature for 3D printing filaments and extending shelf life for fresh vegetables packaged in PLA film. In addition, PLA offers a wide range of end-of-life options: besides mechanical or chemical recycling and (renewable) energy recovery, it offers multiple end-of-life options related to its inherent biodegradability; PLA can be industrially composted or anaerobically digested. In many applications where recycling is a challenge, options such as composting or anaerobic digestion can help to divert organic waste from landfill or incineration. These end-of-life options contribute to circularity through carbon and mineral nutrient recycling, by the application of compost in agriculture soils. In general, managing materials and products for the circular economy requires systemic approaches, including the eco-design to retain resources at highest value for as long as possible through cascading biomass use, re-using and recycling [5].

PLA can be produced from many carbon feedstocks, sourced from various geographic regions through a wide range of technologies, with distinct efficiencies and performances. Regionality and specificity of biobased products are very strong because of the dependency on regional agriculture feedstocks and the maturity of the technologies applied $[2,6]$. It is recognized that there are challenges and knowledge gaps related to the environmental impacts of bio-based chemicals. Bridging these gaps can provide relevant information for academic researchers, brand owners and policy makers on the potential environmental impacts of biobased plastics, recognized as building blocks of the bio-economy and circular economy.

Total Corbion PLA produces PLA in Thailand with the commercial name of Luminy, using lactic acid produced by Corbion. Corbion predominantly uses the highest yielding feedstocks regionally available. In the case of Thailand, the main feedstock is sugarcane but, in time of shortage, the plant can run on alternative feedstocks such as cassava starch. The sugar feedstocks are converted to lactic acid through a fermentation process. Total Corbion PLA, located on the same site, converts the lactic acid into lactide and
PLA in a recently constructed 75 kta PLA polymerization plant.

There are a few published cradle-to-gate LCA studies of PLA based on industrial production processes, the most recent ones being [7, 8]. The study from Vink and Davies [7] is based on a different feedstock and technology and therefore not representative of Total Corbion PLA production. The study of Groot and Borén [8], was based on the design data from 2008 therefore not reflecting completely the currently operating process.

This paper aims at addressing these knowledge gaps by providing cradle-to-gate information on the environmental footprint of PLA produced in Thailand at commercial scale, thus updating the study performed by Groot and Borén [8] when the plants were still in the design phase. The current study uses the latest life cycle inventory (LCI) data and is based on the current industrial production process of lactic acid and the latest design data of the Total Corbion PLA plant. The secondary data collection uses state-of-the-art databases and improved knowledge of the overall value chain. In addition to the improvement of LCI data quality, the environmental impact categories assessed are based on newer methodologies (ILCD $2011+$ ) thoroughly interpreted with new insights over the upstream processes, including newer topics such as water scarcity (WS) footprint and direct land use change (DLUC). The first step of this assessment aims at identifying the most relevant impact categories. For these impact categories, a contribution analysis is carried out to identify potential improvements and knowledge gaps.

Biobased chemicals, including PLA, are still relatively new at industrial scale, therefore making use of less mature technologies than their fossil-based counterpart. For the same reason, these processes have a large improvement and optimization potential. The second part of the article aims at exploring the impact of foreseen supply chain and process improvement measures.

\section{Materials and Methods}

This LCA study is performed according to the standard methodology described in the ISO 14040 series by the International Organization of Standardization (ISO) $[9,10]$. The LCA methodology is structured into four main steps: goal and scope definition, inventory analysis, impact assessment, and interpretation. This study is based on the third-party peer-reviewed cradle-to-gate LCA of lactic acid and lactide [11] and follows the LCA approach for Corbion's product portfolio [12] for the conversion of lactide to PLA. The EU Product Environmental Footprint (PEF) framework is used to provide guidance on methodological decisions which are still open to the practitioner choice in the ISO standard e.g., [13-16]. 
The LCA model was created using the SimaPro Developer software version 8.4.0 developed by PRé Consultants.

\section{Goal and Scope Definition}

This LCA study aims at (1) quantifying the environmental footprint of PLA produced at Total Corbion PLA site in Rayong, Thailand, (2) identifying the critical environmental aspects in the PLA production chain to facilitate systems optimization towards lower overall impacts, and (3) analysis of the environmental impacts of foreseen improvements in the supply chain and PLA production process. The entire value chain is considered, including the growing of sugarcane, the impacts of raw sugar production, the subsequent production of lactic acid from raw sugar by Corbion and the conversion of lactic acid to lactide and PLA by Total Corbion PLA. Because PLA is an intermediate used in product formulations by third parties, the system boundaries are cradle-to-gate.

\section{Process Description}

The production of PLA has four main stages: (1) sugarcane production and transport to sugar mill; (2) sugarcane conversion into raw sugar; (3) fermentation of raw sugar from sugarcane to produce lactic acid by Corbion and (4) conversion of lactic acid into lactide and PLA by Total Corbion PLA. The diagram representing the production of PLA is given in Fig. 1.

\section{Sugarcane}

In Thailand, sugarcane is cultivated in 47 provinces and covers about $8 \%$ of the total arable agricultural land [17]. General sugarcane cultivation practice includes land preparation, planting, maintenance and harvesting stages. In the planting stage, fertilizers are required. Most farms use chemical fertilizers; some use both chemical and biofertilizers. In some farms close to the sugar mill, filter cake from the sugar mill is used as a soil conditioner before planting. Through this practice carbon and mineral resources are recycled and crop yields are improved [18]. Most cane-growing areas are rain-fed (only 10\% are planted in irrigated zones), especially in the Northeastern and Central regions where the major cane growing areas are found. Weeding and pesticide are the general practices in crop maintenance [19-21]. Most sugarcane farms are small (52\%) and medium (31\%) size farms, with an annual production capacity from about 1000 to 2000 tons respectively. The small size of the plantations hinders widespread mechanical harvesting. Harvesting takes place annually and is therefore mostly manual (90\%). Farmers still practice burning, because pre-harvest burning eases manual harvesting. In other cases, sugarcane is manually harvested green and the cane residues (tops and leaves) in the fields are burnt after harvesting, to quickly remove these residues from the fields $[17,19,20]$. According to the office of cane and sugar board of Thailand, in 2012 about $60 \%$ of sugarcane residues were burnt in the open field [17]. Corbion's main supplier of sugar has a target to reduce cane burning to $30 \%$ in 2020 . Burning is not desirable because it reduces sugar yields, releases a number of air pollutants and impacts the soil quality. Sugar mills reward "green cane" harvesting through several incentives including the payment of a premium. During the harvesting period, sugarcane is transported to the sugar mill and is processed immediately.

\section{Sugar Mill}

In the sugar mill, the cane is crushed to extract cane juice. Bagasse, the fibrous material that remains after crushing, is burned to produce electricity and heat. The energy produced is used within the mill and is enough to meet the process requirements. In many cases, there is an excess electricity production which is sold to the grid.

The cane juice is clarified using heat and small amounts of chemicals used to adjust the $\mathrm{pH}$ and prevent the inversion of sucrose. The heavy precipitate that is formed is separated from the juice by filtration. The filter cake is mainly used as a soil conditioner [22]. The clarified juice is evaporated, crystallized, and centrifuged to produced raw sugar and molasses. Molasses are used to produce molasses-based ethanol, which is used as transportation fuel in Thailand.

\section{Lactic Acid}

Corbion produces lactic acid through the fermentation of cane sugar. The $\mathrm{pH}$ of the fermentation is controlled using lime resulting in the formation of calcium lactate. Nutrients are added to aid the fermentation. The fermentation broth is concentrated and calcium lactate is acidulated with sulfuric acid $\left(\mathrm{H}_{2} \mathrm{SO}_{4}\right)$ to recover crude lactic acid. This step also results in the precipitation of gypsum $\left(\mathrm{CaSO}_{4}\right)$, a by-product of the lactic acid process which is removed by filtration.

The final step is the lactic acid purification which removes various impurities. This separation results in another byproduct, stillage. Stillage has multiple applications such as animal feed, biogas production, and bio-fuel.

\section{Lactide and PLA}

PLA is produced by Total Corbion PLA through the polymerization of lactide, which is produced from purified lactic 


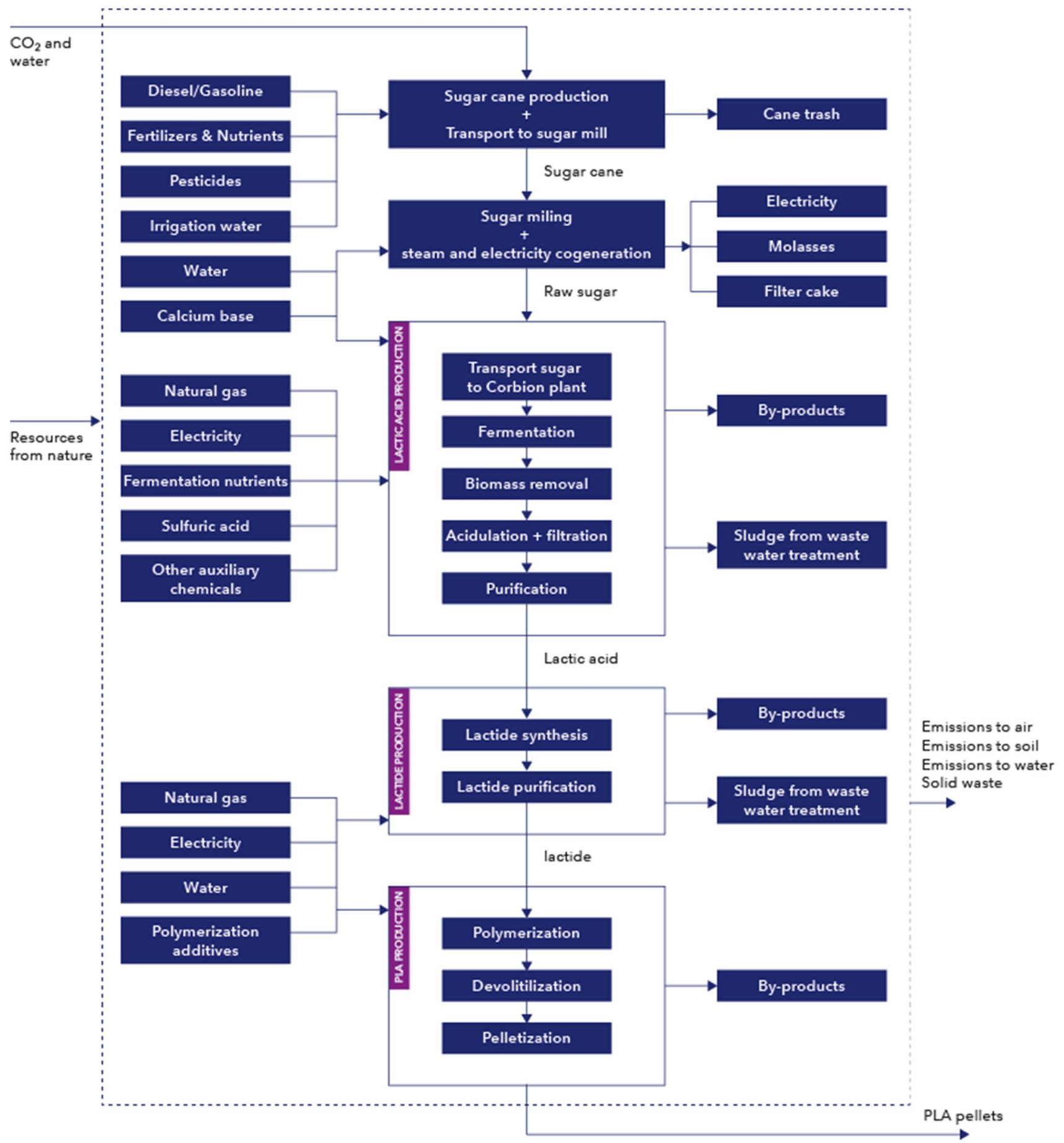

Fig. 1 Simplified flow diagram for the manufacture of PLA. The dotted line represents the system boundary. The wastewater treatment plant is included in the system boundaries. The primary inputs listed on the left side of the flows diagrams. All emissions are listed on the right side

acid. After the polymerization is complete, any remaining lactide monomer is removed and recycled within the PLA production process. To produce PLA pellets, the polymer is further purified. The main input for these manufacturing steps is energy.

\section{Multi-functionality}

PLA production has multiple by-products, as identified in Fig. 1, which are considered in the LCA model taking the multi-functionality hierarchy described in $[10,23]$. The primary data is already divided by products whenever 
Table 1 Overview of by-products from PLA production and multi-functionality approach applied

\begin{tabular}{|c|c|c|c|}
\hline Process step & By-product & Utilization & Avoided product/quantity \\
\hline \multirow[t]{3}{*}{ Sugar mill } & Electricity & $\begin{array}{l}\text { Fuel for co-generation. Excess electricity exported } \\
\text { to the Thai national grid }\end{array}$ & Electricity (Thai grid mix)/supplier information \\
\hline & Molasses & Used for production of ethanol & Conventional gasoline/[24, 25] \\
\hline & Filter cake & Used as soil conditioner & $\begin{array}{l}\text { Gypsum, nitrogen and phosphate/based on composi- } \\
\text { tion [22] }\end{array}$ \\
\hline \multirow[t]{3}{*}{ Lactic acid } & Fermentation residue & Used as soil conditioner & $\begin{array}{l}\text { Gypsum, nitrogen and phosphate/calculated based on } \\
\text { composition }\end{array}$ \\
\hline & Gypsum & Recycled: agriculture (56\%) and construction (44\%) & Mined gypsum/replacement on dry mass basis \\
\hline & stillage & $\begin{array}{l}\text { Fuel in cement kiln (30\%) and animal feed and } \\
\text { biogas application }(70 \%)\end{array}$ & $\begin{array}{l}\text { Heat from coal/based on heating value } \\
\text { Economic allocation (market price) }\end{array}$ \\
\hline \multirow[t]{2}{*}{ PLA } & Lactide recycle & $\begin{array}{l}\text { Reused in the lactide or lactic acid production } \\
\text { process }\end{array}$ & $\begin{array}{l}\text { Sugar/lactic acid } \\
\text { Based on the stream composition }\end{array}$ \\
\hline & PLA recycle & $\begin{array}{l}\text { Reused in the PLA, lactide or lactic acid production } \\
\text { process }\end{array}$ & $\begin{array}{l}\text { Lactic acid and Lactide } \\
\text { Based on lactide content of the recycle stream }\end{array}$ \\
\hline
\end{tabular}

subdivision is possible. Therefore, following the ISO hierarchy system expansion is the preferred approach, applied whenever the substituted product is identifiable.

Table 1 summarizes the current utilization of Corbion and Total Corbion PLA by-products and the modelling assumptions. System expansion is applied to all by-products except the share of stillage that is used for animal feed. The byproduct stillage contains a mixture of lactic acid, carbohydrates and proteins. In addition to the nutritional value, lactic acid in the product has benefits for animal health. Because of this composition, stillage has unique functionalities that do not truly replace a known material or chemical. For this reason, economic allocation is applied to the stillage by-product.

\section{Environmental Impact Categories}

The 16 environmental impact categories from ILCD 2011 Midpoint + are considered for the hotspot analysis. Additionally, because of its widespread use, Cumulative energy demand v1.09 is included in the assessment. The methods are applied as implemented in SimaPro 8.4.

Normalization and weighting are two optional elements of LCIA (Life cycle impact assessment), used in this study to identify the most relevant impact categories. The ISO 14044 standard defines normalization as the "calculation of the magnitude of the impact indicator results relative to reference information" and weighting as the "conversion and possible aggregation of indicator results across impact categories using numerical factors based on value-choices". According to PEF (Product Environmental Footprint) draft methodology, the most relevant impact categories are those cumulatively contributing to at least $80 \%$ of the total environmental impact, [14, 26], starting from the largest to smallest contributions. In the current study, normalization is calculated using the normalization factors per person for the EU 27 from 2010 and equal weighting among categories [26]. Following this recommendation, the toxicity related impact categories are excluded from the hotspot analysis $[13,14,26]$. Interpretation of LCIA results and process hotspot analysis is performed using the characterization results before normalization and weighting.

\section{Carbon Storage in Biobased Products}

When accounting for biogenic carbon in biobased materials, two principal approaches can be used [27]:

(1) Biogenic carbon is accounted for as carbon storage, thus considering that $\mathrm{CO}_{2}$ is captured from the atmosphere during photosynthesis and retained within the bio-based material (cradle to gate LCA).

(2) Biogenic carbon is considered to be $\mathrm{CO}_{2}$ neutral and excluded from the inventory analysis at the end of life phase (cradle to grave LCA).

Because of the scope of this study is cradle-to-gate approach (1) is followed, as recommended for biobased chemicals [23, 27]. The $\mathrm{CO}_{2}$ uptake from the atmosphere, calculated using the biomaterial storage approach [27] is $1.833 \mathrm{~kg} \mathrm{CO} / \mathrm{kg}$ PLA. It is important to note that this storage is reversible and adds carbon emissions in the future, when the product is incinerated or biologically degraded at its end-of-life.

\section{Life Cycle Inventory (LCI)}

The following primary data were collected, with reference to 2016 : 
Table 2 Modifications to the original sugarcane dataset from Agri-footprint V2.0 to reflect the current Thai practice

\begin{tabular}{ll}
\hline $\begin{array}{l}\text { Parameter } \\
\begin{array}{l}\text { Direct land } \\
\text { use change } \\
\text { (DLCU) }\end{array}\end{array}$ & $\begin{array}{c}\text { Use the weighted average DLUC from a key Corbion supplier. For the remaining sugar, the Thai average DLUC } \\
\text { is used }\end{array}$ \\
$\begin{array}{ll}\text { Irrigation } \\
\text { Harvesting }\end{array}$ & $\begin{array}{l}\text { Irrigation water based on 10\% of the theoretical requirement of sugarcane in Thailand, reflecting the local practice } \\
\text { Changes related to manual harvesting and burning: (i) Less diesel used for mechanical harvesting; (ii) Lower } \\
\text { direct and indirect emissions from crop residues on the field and (iii) Addition of direct emissions to air due to } \\
\text { the crop residue burning }\end{array}$ \\
$\begin{array}{ll}\text { Sugarcane yield } \\
\text { Average yield in Thailand in 2011-2014: } 76.3 \text { ton/ha/year }\end{array}$ \\
\hline
\end{tabular}

- Input and output flows from the sugar mill are based on supplier information, including amounts of by-products and wastewater. The emissions to air from bagasse burning are based on Agri-footprint V2.0.

- Lactic acid production based on operation data from Corbion Thailand in 2016, including actual consumptions of materials, water and energy and the process outputs in terms of waste, wastewater and by-products.

- Lactide production and polymerization step: based on the most recent conceptual engineering design from Total Corbion PLA in 2018. The full-scale plants started operating in 2018 and, for this reason, representative production data are still lacking.

- Transport of raw materials used distances from suppliers and assumes truck freight transport.

Secondary data is based on public databases (Ecoinvent v3.3, allocation default), adapted to the Thai situation whenever better-quality data is available. The agriculture process of growing sugar cane is based on Agri-footprint V2.0 'Sugar cane, at farm/TH Economic' modified according to Table 2.

Direct land use change (DLUC) refers to the transformation from the original use of land (e.g., forest, grassland, annual crop etc.) to sugarcane plantations. Depending on the previous use of the land in question, the land change can unlock some of the carbon in existing soil and vegetation. DLUC is included in the calculation. In 2017 GRAS GmbH conducted a sustainability risk analysis for Corbion. This study is based on high-resolution satellite images and enhanced vegetation index (EVI) time series analysis, with focus on LUC, protected areas and carbon stock covering the plantations around the key Corbion sugar supplier (50 km radius). According to this study, in the area assessed the percentage of land converted to cropland is very low: $<0.057 \%$ from forest, $0.005 \%$ from shrubland and $0.015 \%$ from tree plantations [28]. For the remaining sugar supply, the Thai weighted average DLUC is used, based on agricultural statistics between 1992-2011 which estimate an expansion area to sugarcane crop of $25 \%$. This expansion occurs due to the conversion of forest (13\%), perennial crops (1\%) and annual crops (11.8\%) [29].

The second component of land use change is indirect land use change (iLUC), which covers secondary effects induced by large-scale expansion. The displacement of existing crops potentially leads to the expansion of cropland elsewhere. iLCU impacts are out of the scope of the current study because the methodologies for iLUC calculation rely on assumptions that strongly affect the results while still lacking scientific consensus [33-35]. The GHG emissions from iLUC can have a significant impact on the GWP of bio-based plastics, as shown in studies for biofuels using similar carbohydrate feedstocks, which are not captured in this study [36, 37, 30].

Natural gas is used to produce the heat required for the various conversion steps of sugar to PLA. Ecoinvent 3.3 is used as LCI input for the emissions related to natural gas production and combustion and for the Thai electricity grid mix. The same database is used for datasets related to the production of chemicals (including lime and sulfuric acid) again adapted to Thailand for the inputs of electricity, heat and water.

\section{Results and Discussion}

The LCIA results for the 8 most relevant impact categories are shown in Table 3:

- Global warming potential (GWP), water depletion (WS), marine and terrestrial eutrophication potential (EP), acidification potential (AP) and particulate matter (PM) were selected based on their relative contribution of the normalized and weighted results. Together, these five categories cumulatively contribute to more than $80 \%$ of the environmental impact.

- The inclusion of three additional impact categories, land use (LU) and cumulative energy demand (CED), split in renewable and non-renewable energy use, is justified by their relevance to the debate over the environmental sustainability of biobased chemicals. 
Table 3 Relevant cradle-to-gate impact assessment categories for 1 ton of PLA

\begin{tabular}{lll}
\hline Impact category & Unit & Total \\
\hline Global warming potential (GWP) & $\mathrm{kg} \mathrm{CO}_{2}$ eq & $501\left(2334^{\mathrm{a}}\right.$ ) \\
Water resource depletion (WS) & $\mathrm{m}^{3}$ water eq & 36.1 \\
Marine eutrophication (EP) & $\mathrm{kg} \mathrm{N} \mathrm{eq}$ & 13.3 \\
Terrestrial eutrophication (EP) & molc N eq & 33.8 \\
Acidification (AP) & molc H+eq & 18.2 \\
Particulate matter (PM) & $\mathrm{kg} \mathrm{PM} \mathrm{2.5} \mathrm{eq}$ & 1.74 \\
Land use (LU) & $\mathrm{kg} \mathrm{C} \mathrm{deficit}$ & 17,441 \\
Renewable energy use (REU) & GJ & 60.4 \\
Non-renewable energy use (NREU) & GJ & 28.8 \\
\hline
\end{tabular}

GWP includes direct land use change, excludes biogenic emissions and includes the $\mathrm{CO}_{2}$ uptake by the bio-based material

${ }^{\text {a }}$ Total fossil GWP excluding the $\mathrm{CO}_{2}$ uptake
The next sections focus on the hotspot analysis and interpretation of these 8 impact categories, summarized in Table 4.

\section{Global Warming Potential (GWP)}

From a cradle-to-gate perspective, considering the uptake of carbon dioxide in the PLA molecule, the GWP is $501 \mathrm{~kg}$ $\mathrm{CO}_{2}$ eq/ton PLA. Figure 2 and Table 4 show the breakdown of the contributions of the different production stages to the total GWP of PLA.

The starting point for the GWP of PLA was the $\mathrm{CO}_{2}$ uptake from the atmosphere by the growing sugarcane. The amount of $\mathrm{CO}_{2}$ fixated in the PLA material was $1833 \mathrm{~kg} \mathrm{CO}_{2} /$ ton PLA, according to the biomaterial storage approach. In cradle-to-grave assessments, this $\mathrm{CO}_{2}$ must be included in

Table 4 Relevant environmental impact potentials to produce 1 ton of PLA divided across different stages of the production system

\begin{tabular}{|c|c|c|c|c|c|c|c|}
\hline & $\begin{array}{l}\mathrm{GWP}\left(\mathrm{kg} \mathrm{CO} \mathrm{CO}_{2}\right. \\
\text { eq) }\end{array}$ & $\begin{array}{l}\text { Marine eutrophi- } \\
\text { cation (kg N eq) }\end{array}$ & $\begin{array}{l}\text { Terrestrial eutroph- } \\
\text { ication (mol } \mathrm{N} \text { eq) }\end{array}$ & $\begin{array}{l}\text { Acidification } \\
\text { potential (molc } \\
\mathrm{H}+\mathrm{eq})\end{array}$ & $\begin{array}{l}\mathrm{PM}(\mathrm{kg} \\
\mathrm{PM} 2.5 \mathrm{eq})\end{array}$ & NREU (GJ) & $\overline{\operatorname{REU}(\mathrm{GJ})}$ \\
\hline $\mathrm{CO}_{2}$ uptake & -1833 & - & - & - & - & - & - \\
\hline Sugarcane production & 406 & 10.1 & 16.8 & 3.7 & 0.3 & 1.3 & 61.6 \\
\hline Sugar mill & -211 & 0.4 & 0.4 & 1.0 & 0.6 & -6.2 & 0.9 \\
\hline Lactic acid production & 1448 & 2.3 & 14.8 & 11.7 & 0.8 & 22.8 & 0.6 \\
\hline Lactide production & 524 & 0.2 & 1.7 & 1.1 & 0.1 & 8.7 & -1.7 \\
\hline PLA production & 167 & 0.4 & 1.1 & 0.5 & 0.0 & 2.2 & -1.0 \\
\hline Total & 501 & 13.9 & 34.8 & 18.2 & 1.7 & 28.8 & 60.4 \\
\hline
\end{tabular}

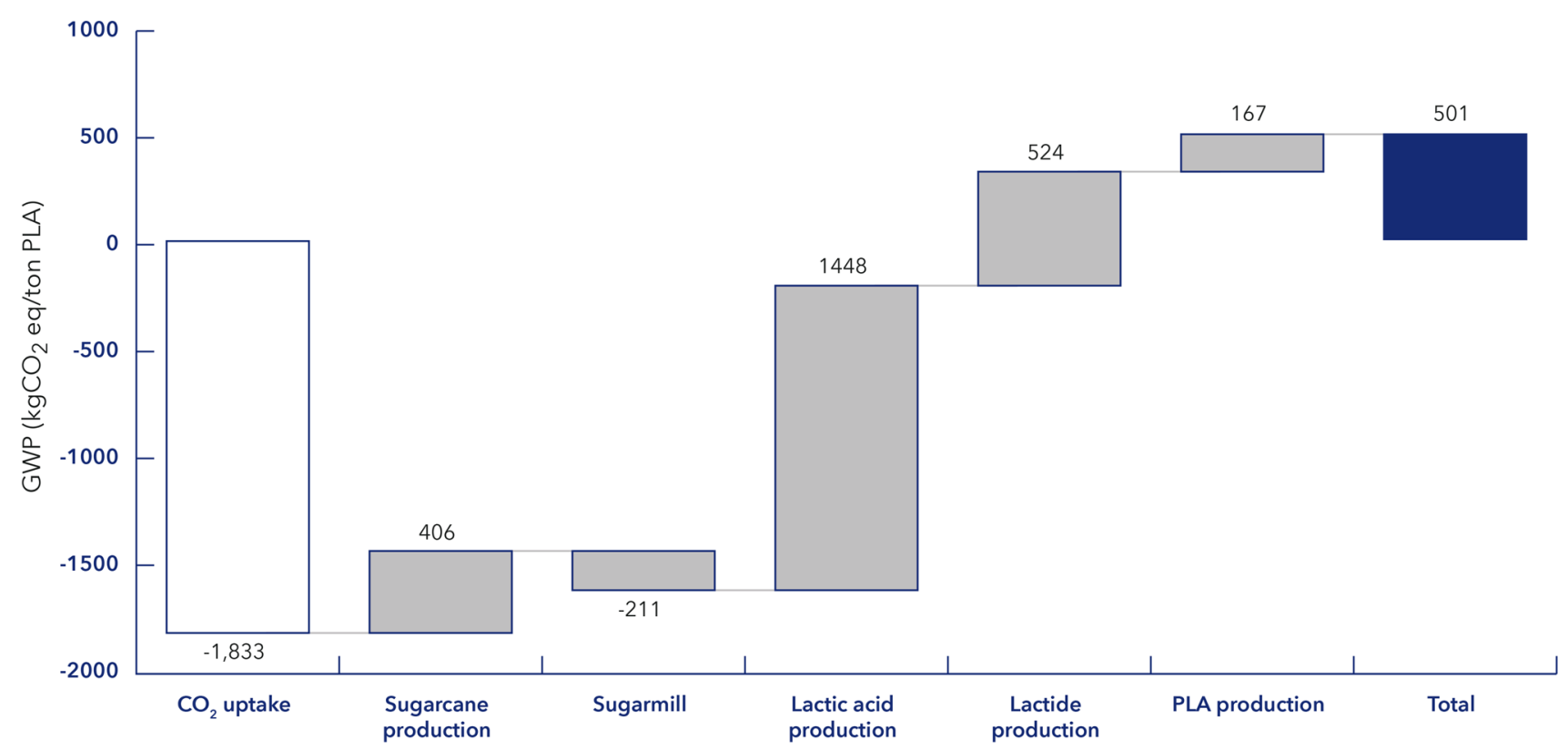

Fig. 2 Contribution of the different production stages to the total GWP of PLA, starting with $\mathrm{CO}_{2}$ uptake during sugarcane growth up to, and including, PLA pellets production 


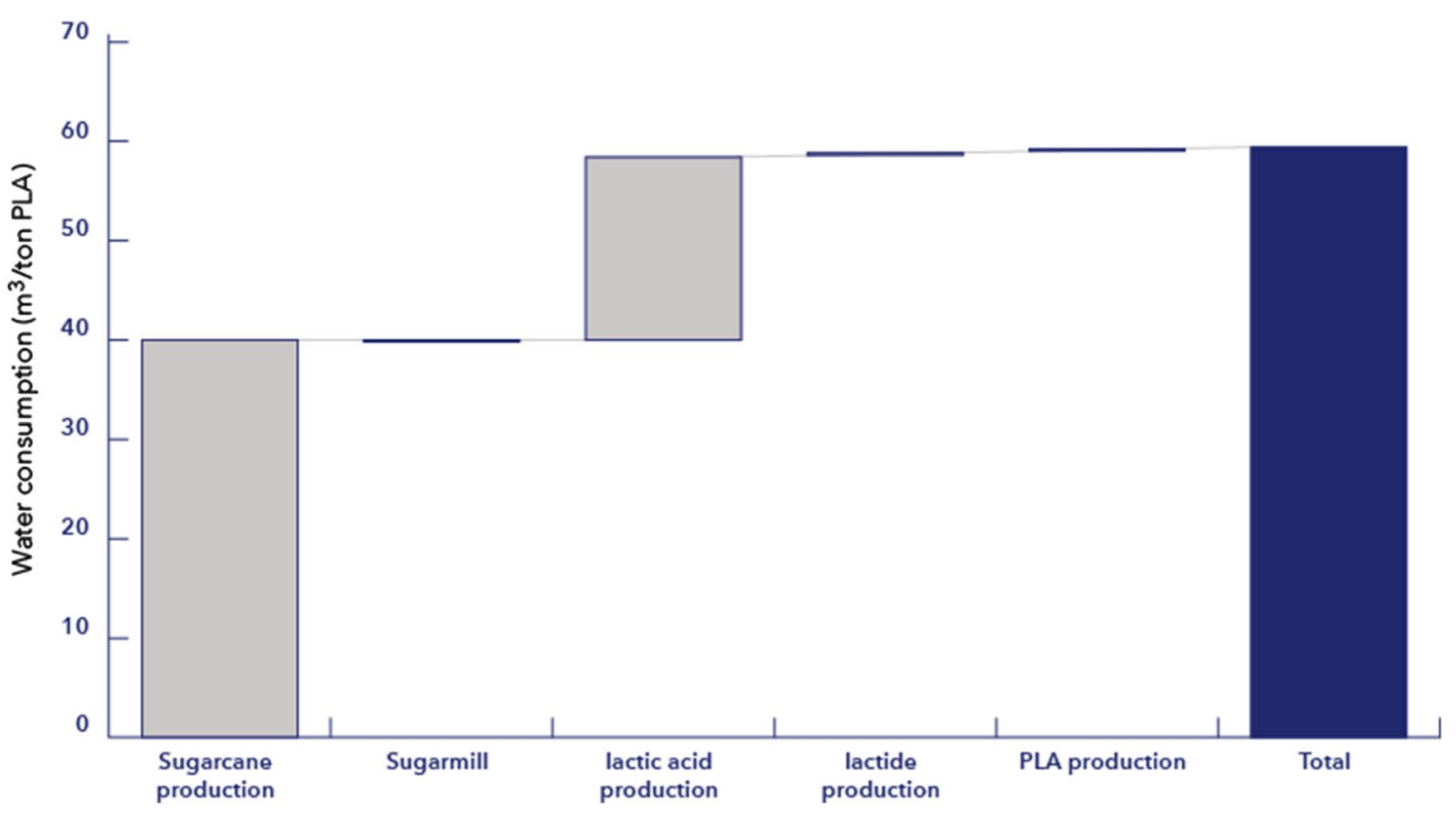

Fig. 3 Contribution analysis to water consumption for the production of PLA

the footprint as it will be released at the end-of-life of the product.

The GHG emissions related to the sugarcane production were mainly due to $\mathrm{N}_{2} \mathrm{O}$ emissions resulting from the application of nitrogen fertilizers and crop residues (42\%) and to DLUC (30\%). The remaining $28 \%$ of the sugarcane production emissions comprised all other farming activities such as fuel for agricultural machinery, production of fertilizers and GHG emissions from burning of sugarcane residues on the field. $\mathrm{N}_{2} \mathrm{O}$ emissions directly or indirectly originating from fertilizer application have a large degree of uncertainty: the amount of fertilizers used in the inventory is based on proxy data and, in general, the agricultural emissions are extremely difficult to measure or to calculate with precision [33]. Recent literature studies have collected data from specific Thai sugarcane plantations, showing that the amount, type and application frequency of fertilizers varies significantly from plantation to plantation $[19,20]$. Such variability is likely to apply to the Corbion supply chain as well, meaning that the high uncertainty on the $\mathrm{NO}_{2}$ emissions should be considered when interpreting the results. The net impacts of the sugar mill resulted in a negative
GWP because the credits from the by-products outweigh the small amounts of chemicals and energy consumed to make the raw sugar. The steam and electricity used in the mill are co-generated from bagasse. The by-products, electricity, molasses and filter cake, are used to avoid the production of electricity, gasoline and soil conditioners. Electricity was by far the most important by-product in terms of contribution to GWP.

The biggest contributor to the GWP of PLA was the lactic acid step. These GHG emissions were largely related to the consumption of energy, which accounts for $40 \%$ of the total emissions. The chemicals used during lactic acid production had the following contributions: lime $34 \%$, sulfuric acid $6 \%$ and other chemicals $9 \%$. The large impacts of lime are related to the direct $\mathrm{CO}_{2}$ emissions during limestone calcination and fuel combustion in the kiln. Transport of raw materials to the Corbion site accounted for $13 \%$ of the emissions. The by-products generated, gypsum, biomass and stillage, were valorized and had a small negative contribution $(-2 \%)$.

Lactic acid, is an important intermediate product used for PLA production (Fig. 1) but also can also be used as ingredient for other applications. The total cradle-to-Corbion plant gate GWP of lactic acid was $-224 \mathrm{~kg} \mathrm{CO}_{2}$ eq/ton including all inputs and outputs from farm to lactic acid final product. ${ }^{1}$

\footnotetext{
1 The $\mathrm{CO}_{2}$ uptake of lactic acid is $1467 \mathrm{~kg} \mathrm{CO}$ eq/ton lactic acid, calculated according to the biomaterials storage approach as described in the materials in methods.
} 
The GHG emissions from the lactide and PLA production steps were mainly related to natural gas and electricity consumed by the plant.

\section{Water Consumption and Water Depletion}

Figure 3 shows the freshwater consumption ${ }^{2}$ required for PLA production, which is dominated by the irrigation water. The water consumption for irrigation included in the LCI is $10 \%$ of average theoretical requirement based on the crop evapotranspiration rate and the rainfall in Thailand [30], because Thai cane areas are primarily rain fed and only about $10 \%$ of sugarcane cultivation area is irrigated $[17,39]$.

The water consumption in the sugar mill is low because the treated water effluent from the mill is returned and reused to irrigate the nearby farms. In PLA production the most water intensive step is the lactic acid fermentation. This water is supplied by the industrial complex reservoirs which collect rainwater. Most of the water is recovered in the purification process and re-used or discharged for the wastewater treatment. The water consumption includes only water evaporation in the cooling towers and water in by-products.

Water scarcity (WS) ${ }^{3}$ is increasingly considered to be an important impact category for environmental footprints and agriculture is the most water consuming sector [33]. However, the LCIA methods for water scarcity have a low maturity level compared to other impact categories, with a significant number of recent publications proposing new models in recent years. Meaningful impact results for water scarcity require specific water consumption data and spatially differentiated characterization factors.

For the identification of the most relevant impact categories, the method 'Water depletion' was used, along with the normalization factors from ILCD 2011 Midpoint +, as implemented in SimaPro 8.4. Water depletion refers to freshwater consumption in relation to local scarcity of water [15].

However, recent publications by the PEF commission recommend the replacement of the Water depletion method by AWARE (Available WAter REmaining) [14]. AWARE is a water use midpoint indicator representing the relative available water remaining per area in a watershed after the demand of humans and aquatic ecosystems has been met. It assesses the potential of water deprivation, to either humans or ecosystems, building on the assumption that the less water remaining available per area, the more likely another user will be deprived [41]. The water scarcity indicator calculated with these two methods is:

\footnotetext{
2 Water consumption refers to loss of water from the available ground-surface water body in a catchment area. Losses occur when water evaporates, returns to another catchment area or the sea or is incorporated into a product [38].

${ }^{3}$ Water scarcity is defined as "extent to which demand for water compares to the replenishment of water in an area, e.g., a drainage basin, without taking into account the water quality" [40].
}

- Water depletion: $36.01 \mathrm{~m}^{3}$ eq/ton PLA.

- AWARE: $786 \mathrm{~m}^{3}$ eq/ton PLA.

The magnitude of the difference between the values reflects the different theoretical background for the LCIA models applied and cannot be directly compared. The different contributions to the overall value follow the same distribution as the water consumption volumes shown in Fig. 3.

The LCA characterization factors used for both water scarcity characterization methods are country-specific. While this is a good first estimate, a more detailed analysis at basin level is recommended [33]. For this reason, the baseline water stress was checked for the cultivation areas around the sugar mills, using a water risk assessment tool [42]. The baseline water stress measures the ratio of total annual water withdrawals to total available annual renewable supply, accounting for upstream consumptive use. Figure 4 shows the water stress map of Thailand indicating the location of two main Corbion sugar suppliers and the Corbion and Total Corbion PLA manufacturing sites. The sugar plantations of the North-East region and the PLA manufacturing site are in low water stress regions. The plantations in the central region are in a low/medium water stress area, which is also the regions with lower water requirement [30].

\section{Eutrophication Potential (EP)}

Aquatic eutrophication is defined as nutrient enrichment of the aquatic environment. It is subdivided into two different impact categories: marine eutrophication, which considers the nitrogen enrichment of seawater and freshwater, and freshwater eutrophication, which includes only phosphor enrichment of freshwater [43]. Terrestrial eutrophication, on the other hand, is a consequence of deposition of aerial nitrogen compounds such as $\mathrm{NO}_{\mathrm{x}}$ and $\mathrm{NH}_{3}$ on terrestrial ecosystems, also resulting in increased nutrient availability.

Table 4 shows the contribution of the different production stages to the marine eutrophication and terrestrial eutrophication of PLA. Sugarcane production accounts for $76 \%$ of the impact on marine eutrophication and $50 \%$ of terrestrial eutrophication, driven by the fertilizer and manure use. The uncertainty on the amount of fertilizer used is related to inventory data quality and emission model, in a similar way to what was discussed for the impact of $\mathrm{N}_{2} \mathrm{O}$ emissions on GWP.

In the remaining stages, the impacts on eutrophication were largely related to the lactic acid production, more specifically to the wastewater emissions of nitrogen containing compounds to water and air. The additional inputs adding up to terrestrial eutrophication are the $\mathrm{NO}_{\mathrm{x}}$ emissions to air from combustion processes in general: transport, electricity production and production of the chemicals used in the process such as lime and sulfuric acid. 
Fig. 4 Baseline water stress map in Thailand adapted from WRI aqueduct water risk atlas [42]. Higher values indicate a higher water stress. The map shows the location of two sugar mills and the Corbion and Total Corbion PLA manufacturing site in Rayong

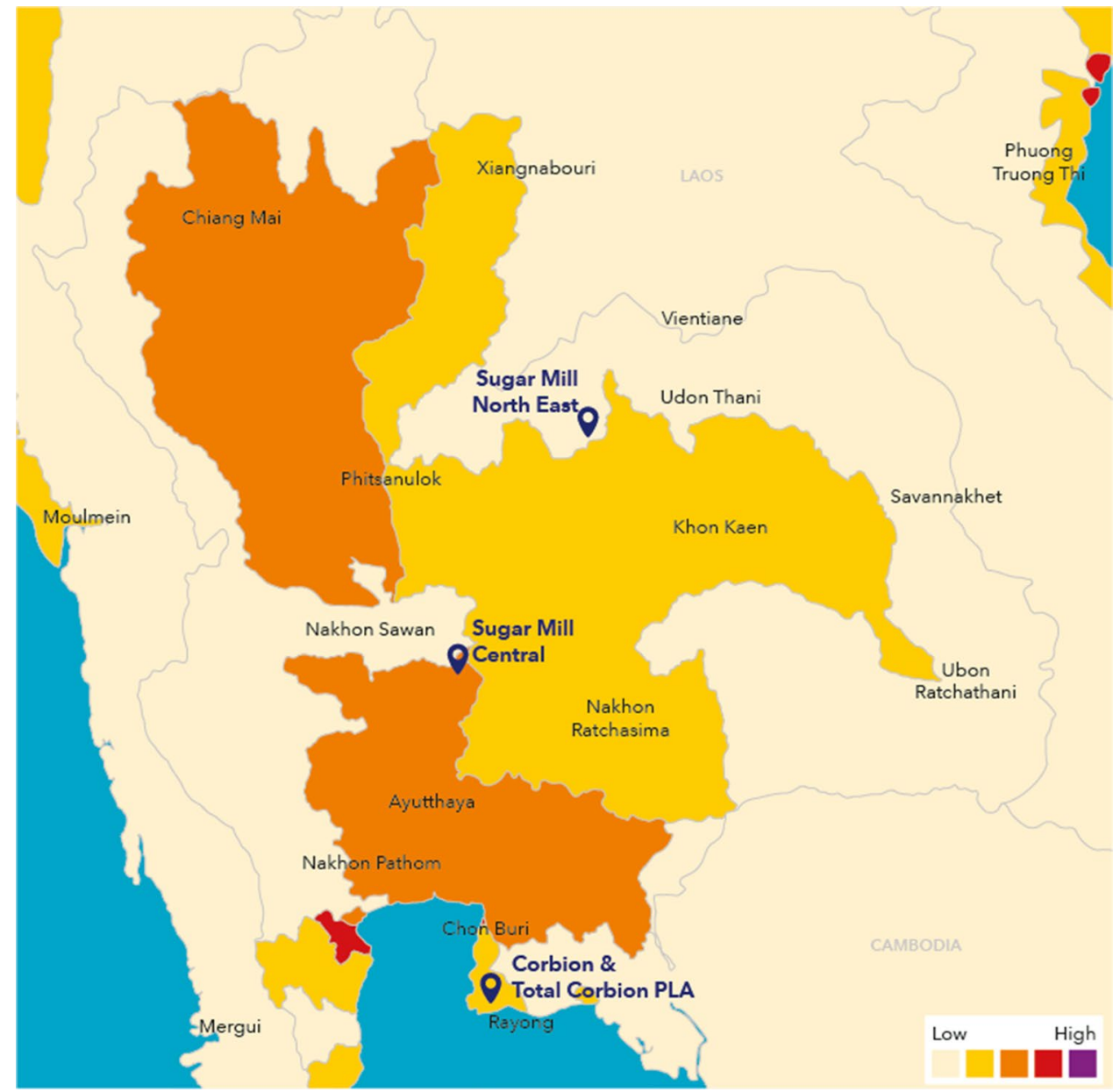

\section{Acidification Potential}

Acidification is mainly caused by air emissions of $\mathrm{NH}_{3}, \mathrm{NO}_{2}$ and $\mathrm{SO}_{\mathrm{X}}$ which, when deposited in the soil, cause a change in its acidity. Most ecosystems have an optimal acidity and a deviation from those conditions is harmful.

According to Table 4, the largest impact on acidification was the lactic acid production stage, driven by sulfur dioxide and nitrogen oxides emissions. These emissions to air occur during the production of the chemicals used in this manufacturing step (mainly sulfuric acid) as well as during the transport of raw materials and energy generation for the process (both electricity and natural gas). The second most relevant process was the sugarcane production. Similarly to terrestrial eutrophication, the acidification potential is caused by ammonia and nitrogen oxide emissions derived from fertilizer and manure application.

\section{Particulate Matter (PM)}

The impact category of particulate matter/respiratory inorganics is a measure of the intake fraction for fine particles which negatively affect human health. The RiskPoll model includes the assessment of primary PM (PM10 and PM2.5) and $\mathrm{PM}$ precursors - for example, the creation of secondary $\mathrm{PM}$ due to $\mathrm{SO}_{\mathrm{x}}, \mathrm{NO}_{\mathrm{x}}$ and $\mathrm{NH}_{3}$ emissions, and $\mathrm{CO}$ [16].

Table 4 shows that most of the emissions were related to the upstream production of sugar and sulfuric acid. The main contributing processes were: (i) emissions of $\mathrm{SO}_{\mathrm{x}}$ and particulates from sulfuric acid production which is used in the lactic acid production (17\%), (ii) particulate emissions from open burning of cane fields (17\%) and (iii) bagasse combustion in the sugar mill (22\%). The additional emissions were spread throughout the process, due to related combustion processes including transport, as well as steam and electricity production.

\section{Land Use}

Land is required to produce bio-based materials as well as to produce food, feed and biofuels. Land use is an important topic for biobased materials, as land use and changes in land use can lead to unintended environmental impacts; by 
definition, the production of biobased materials require more land area than the fossil-based counterparts.

Land use depends on many factors such as: crop type, average local and regional yields, the allocation procedure used to account for the multiple crop products, the percentage of fermentable sugars in the crop and the efficiency of recovery of these sugars along with the efficiency of the conversion steps to PLA. The land occupation ${ }^{4}$ required to produce 1 ton of PLA from Total Corbion PLA is $1775 \mathrm{~m}^{2}$ per year.

Annual Thai sugarcane production is about $100,000,000$ ton, with an average yield of 0.10473 ton sugar/ton sugarcane $[17,32]$, which results in about 10,470,000 ton/year of raw sugar. Total Corbion PLA utilizes a maximum of 150,000 tons of raw sugar annually, representing around $1.4 \%$ of the Thai sugar production. Thailand has about $16,500,000$ ha of arable land of which about $8 \%$ is used for sugarcane production (average data 2011-2014) [32]. Therefore, the raw sugar used annually by Corbion for the production of PLA at Total Corbion PLA requires an estimated 20,000 ha or $0.12 \%$ of the Thai available arable land.

The inherent limitation of using the occupied surface area, without any further characterization, is that the different land types and associated environmental impacts are not considered. One step further is to include a characterization model based on changes in soil organic matter (SOM) as recommended by ILCD [16]. According to this model, the land use of PLA is $17,444 \mathrm{~kg} \mathrm{C}$ deficit/ton PLA. This model is still interim, not including relevant impacts related to land use such as biodiversity.

Another way to assess biodiversity or deforestation risks is through satellite imaging of the plantations and overlapping the plantation areas with biodiversity protected areas. The 2017 GRAS GmbH sustainability risk assessment for Corbion's main sugar supplier did not identify significant land transformation to sugar plantations in high carbon stock or high conservation value protected areas.

Corbion continuously seeks for the most sustainable sugar sources. In addition to complying with the Corbion Cane Sugar Code, Corbion requires all its cane sugar suppliers to become members of Bonsucro ${ }^{5}$ and expects them to work towards implementation of the Bonsucro Production Standard. Since 2017, Total Corbion PLA offers PLA bioplastic resin made from Bonsucro certified sugar.

\footnotetext{
${ }^{4}$ Sum of agricultural and urban land occupation from ReCiPE 2008.

5 Bonsucro is an international multi-stake holder organization to promote sustainable sugar cane, by setting sustainability standards and certifying sugar cane products [44].
}

\section{Cumulative Energy Demand (CED)}

The CED of a product represents the direct and indirect energy use throughout the life cycle, including the energy consumed during the extraction, manufacturing and disposal of the raw and auxiliary materials. The method used is based on upper heating values. It is subdivided into renewable energy use (REU) and non-renewable energy use (NREU). Table 4 shows the NREU and REU of PLA production. REU was mainly related to the energy content of sugarcane which ends up as sugar for PLA but also as bagasse used as an energy source in the sugar mill. The other renewable energy entries were linked to electricity production using renewable resources. At the sugar mill, the NREU was negative because of the electricity exported to the Thai grid, which uses more than $90 \%$ non-renewable sources in its mix (1). At the Corbion and Total Corbion PLA manufacturing steps, most of the NREU was for lactic acid followed by lactide and PLA. These steps consumed fossil energy as heat and electricity (61\%). In addition, there is indirect energy consumption for the production of chemicals used for lactic acid (30\%) and transportation of raw materials $(9 \%)$.

\section{Sensitivity Analysis}

Based on the results discussion and modelling assumptions, a sensitivity analysis was performed covering the allocation of by-products and inputs with high uncertainty such sugar cane production (total impact, irrigation water and DLUC) and lime productions. The sensitivity ranges and results are summarized in Table 5 showing that the allocation approach for by-products has a low impact, except for molasses.

The assumptions related to sugarcane are critical for most of the impact categories. The sensitivity analysis covered the following parameters: (1) total impacts of sugarcane production, arbitrarily varied in the range $-20 \%$ to $20 \%$ (2) amount of irrigation water used for sugarcane, based on the theoretical water requirement of the crop in Thailand [30] and no irrigation and (3) Direct land use change varied between zero and the Thai average for sugarcane [29]. The impact on water scarcity is most sensitive to irrigation water and GWP is most sensitive to DLUC.

The impacts of lime production are varied in arbitrary range of $-20 \%$ to $+20 \%$ to understand the impact of production process variations such as type of fuel used in the kiln. The results show a moderate impact on GWP. 
Table 5 Sensitivity analysis summary including the parameters considered, their variation range and the results for impact categories with a variation larger than $10 \%$

\begin{tabular}{|c|c|c|}
\hline Parameter & Description and variation range & Sensitivity analysis outcome \\
\hline Sugarcane production & $\begin{array}{l}\text { Overall Impact of sugarcane production varied in } \\
\text { the range }-20 \% \text { to }+20 \%\end{array}$ & $\begin{array}{l}\text { GWP: }-1 \text { to } 3 \% \\
\text { Water footprint: }-7 \% \text { to }+23 \% \\
\text { Marine EP: }-16 \% \text { to } 12 \% \\
\text { Terrestrial EP: }-10 \% \text { to }+12 \% \\
\text { Land use: }-16 \% \text { to }+18 \%\end{array}$ \\
\hline Sugarcane production-irrigation water & $\begin{array}{l}\text { Range } 0-2595 \mathrm{~m}^{3} / \mathrm{ha} \text {. The maximum value is } \\
\text { the theoretical water requirement of the crop in } \\
\text { Thailand [30] }\end{array}$ & Water footprint: $-77 \%$ to $+742 \%$ \\
\hline Sugarcane production-DLUC & $\begin{array}{l}\text { Range } 0-1668 \mathrm{~kg} \mathrm{CO}_{2} \text { eq/ha; maximum DLUC is } \\
\text { the weighted average calculated by [29] }\end{array}$ & GWP: $-5 \%$ to $+12 \%$ \\
\hline Sugar mill by-products & $\begin{array}{l}\text { Economic allocation is used as an alternative for } \\
\text { the by-products bagasse, molasses and filter cake }\end{array}$ & $\begin{array}{l}\text { Molasses show the highest sensitivity: PM } \\
\text { decreases by } 14 \% \text { and NREU increases } 12 \% \\
\text { with economic allocation }\end{array}$ \\
\hline Lime production & $\begin{array}{l}\text { Overall impact of lime production varied in the } \\
\text { range }-20 \% \text { to }+20 \%\end{array}$ & GWP: $-4 \%$ to $+10 \%$ \\
\hline PLA manufacturing by-products & $\begin{array}{l}\text { Economic allocation is used as an alternative for } \\
\text { the by-products gypsum, stillage, biomass and } \\
\text { recycled streams from lactide synthesis and } \\
\text { polymerization }\end{array}$ & Low impact \\
\hline
\end{tabular}

Low impact is defined as less than $10 \%$ difference for all impact categories [23]

\section{Future Scenarios}

The growth of the biobased polymers market, and PLA in particular, is stimulating manufacturers towards economic and environmental optimization, as part of business development strategies. While fossil-based polymers started to be widely commercialized in the 1950s, biobased polymers were developed decades later, and as consequence are still making use of less mature technologies. Undoubtedly, along with the growth of the PLA market, optimizations can be foreseen through the implementation of innovative technologies covering the full value chain. The future scenarios are an exploratory analysis, based on various assumptions and expectations about the future. They reflect possible modifications to the production system that may or may not be implemented by Corbion and/or Total Corbion PLA and/or their supply chain partners.

Starting with the feedstock production, multiple improvements can be envisaged either by continuing using the same sugar crop or new carbon sources. As part of the sustainable sourcing initiative, Corbion works together with its sugar suppliers towards the implementation of the Bonsucro standard. The Bonsucro Production Standard covers the following 5 key principles: obey the law, respect human rights and labor standards, manage input, production and processing efficiencies to enhance sustainability, actively manage biodiversity and ecosystem services and lastly, continuously improve key areas of the social, environmental and economic sustainability [45].
Comparing the Bonsucro production standard with the LCI of sugar in Thailand used in this study, the following improvements can be expected at the farm level:

a. Increased yield of sugarcane above 80 ton/ha. For the sourcing areas, the Bonsucro standard sets a minimum yield [45], adapted to the climate zone under which cane is grown, which is higher than the current input data.

b. Reduced agricultural emissions with impact on acidification to meet the Bonsucro standard requirement of $<0.15 \mathrm{~kg} \mathrm{SO}_{4} /$ sugarcane and $6 \mathrm{~kg} \mathrm{SO}_{4} /$ ton sugar. This is mainly driven by ammonia emissions from manure and nitrogen fertilizers, suggesting that the usage of these fertilizers should decrease to meet the standard requirements. The use of lower amounts of $\mathrm{N}$ and $\mathrm{P}$ has a positive impact on the reduction of eutrophication and acidification, and, indirectly on GWP because of $\mathrm{N}_{2} \mathrm{O}$ emissions.

Bonsucro principles also prevent the cultivation of sugarcane in areas of high conservation value or legally protected $^{6}$ areas of high biodiversity value and high carbon stock or peatlands after 2018. This includes primary forests, nature protected areas, wetlands. Even though the demand for sugarcane is increasing, through sustainable

\footnotetext{
${ }^{6}$ Areas of High Conservation Value include: species diversity, landscape ecosystems and habitats, community needs and cultural values.
} 


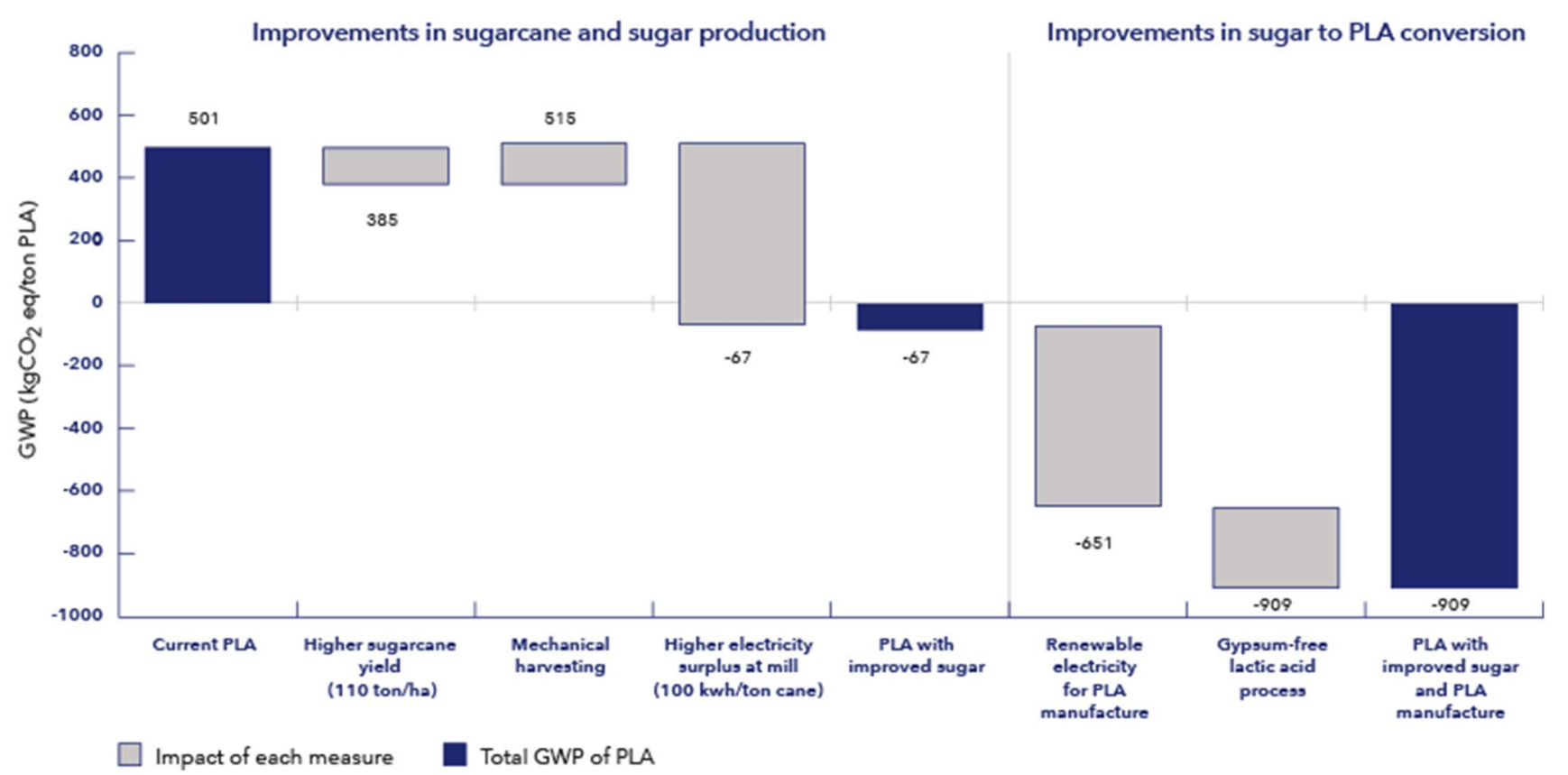

Fig. 5 GWP of PLA future scenarios including: (1) higher sugarcane yield, closer to the genetic potential, (2) mechanical harvesting, (3) increased electricity surplus at the sugar mill, (4) use of renew-

sourcing the biodiversity and GHG emissions linked to land use change should have a limited impact.

At the mill, the consumption of energy is expected to decrease, to meet Bonsucro principles. We can expect that at lower energy use in the mill, with the same bagasse boilers, the electricity surplus will increase and more energy will be exported to the grid. Modern sugar mills with efficient cogeneration system installations generate electrical energy in the range of $115-120 \mathrm{kWh} /$ ton sugarcane [46, 47]

Based on this analysis, and the relevant impact categories analysis in this study, the future scenarios on sugar production cover:

- Sugarcane yield of 110 ton/ha, reaching the genetic potential range of 94-112 ton/ha [30]. Achieving such high yields requires measures to improve soil quality by using organic fertilizers and good practices in land preparation, plantation, harvesting and regular weed control as well as efficient irrigation techniques such as drip irrigation. Also, the use of high yield, drought resistant sugarcane varieties can also contribute to reducing the environmental footprint of sugarcane cultivation systems $[17,30]$;

- Mechanical harvesting and no cane burning. Identified as sustainability requirement [17]; able electricity in the manufacture of PLA from sugars and (2) lower usage of chemicals in the lactic acid process (gypsum-free process)

- The increased amount of electricity exported to the grid to the hypothetical value of $100 \mathrm{kWh} /$ ton cane. This can be attained by two concomitant ways:

- Increasing the energy efficiency of the plant, therefore increasing the energy surplus. This is a requirement for Bonsucro sugar certified, as mentioned above.

- Installing high pressure boilers with high energy efficiency. In the recent years, the co-generation by sugar mills in Thailand has developed to become a strategic part of the business. The new boilers installed are more efficient, meaning that when older boilers are replaced or there is a capacity increase the amount of electricity exported is also expected to increase.

Figure 5 shows the results of these scenarios on GWP, demonstrating that the electricity export has the largest positive impact. Mechanical harvesting results in higher diesel consumption at the farms, therefore resulting in a negative impact on GWP but reducing the particulate matter emissions by $14 \%$. Indirectly, mechanical harvesting is an enabler to maintain the soil quality and achieve higher sugar yields. If the sugarcane yields approach the maximum of 110 ton/ ha, the following reductions can be attained: land use $26 \%$, water consumption $24 \%$, marine eutrophication $24 \%$, terrestrial eutrophication 14\% and GWP 5\%. Given the significant 
Table 6 Main differences in LCI and multi-functionality modelling approach between Groot and Boren [8] and the current study

\begin{tabular}{|c|c|c|}
\hline & Groot and Borén [8] & Current study \\
\hline Sugarcane production & Based on Nguyen et al. [25] DLUC not considered & $\begin{array}{l}\text { Based on Agri-footprint v2.0 (2016), average yields } \\
\text { from 2011-2015 (FAO) and includes DLUC }\end{array}$ \\
\hline Sugar production & Literature data from $2007[25,50]$ & Supplier information (2016) \\
\hline Lactic acid production & Design of Purac 100 kta plant in Thailand (2008) & Corbion operation data (2016) \\
\hline Lactide production & Design of Purac 75 kta plant in Thailand (2008) & Updated Total Corbion lactide and PLA process (2016) \\
\hline PLA production & Design data from 2008 & \\
\hline Electricity mix & International energy agency 2006 & Ecoinvent 3.3, allocation default (2013) \\
\hline By-products & Economic allocation & System expansion \\
\hline
\end{tabular}

impact on several impact categories, actions towards yield improvement are recommended.

The conversion stage of sugar to PLA also offers opportunities for improvement. Through the contribution analysis, two key aspects were identified: the consumption of energy and the production of chemicals used for the lactic acid process (Fig. 2 and Table 4). Corbion and Total Corbion PLA both continuously work to improve their resource efficiency. One of the expected future developments is that electricity will be sourced from renewables due to Corbion's target to source $100 \%$ renewable electricity by 2030 . The second expected development is the implementation of a gypsumfree technology for lactic acid, thereby diminishing the consumption of major chemicals. The gypsum-free process can be achieved using different microorganism that can produce lactic acid at low $\mathrm{pH}$ or through changes in the overall process such as, for example, by applying electrodialysis and/or membrane-based separations [48]. Despite the high potential of these alternative processes they require large modifications in the manufacturing facilities and are likely to be implemented only in new plants. The use of renewable energy has a significant impact ( $>10 \%$ reduction) on GWP and NREU while the gypsum-free process also reduces particulate matter and acidification.

Currently, sugar-based feedstocks are the most efficient and sustainable crops; sugarcane is recognized as the most efficient bioenergy crop of the tropical and subtropical regions [47, 49]. However, R\&D teams continue to work on new production processes for biochemicals and biobased plastics made from agricultural waste and other non-food feedstocks. The use of these feedstocks can potentially decrease the farm related impacts such as GWP, eutrophication and water consumption. In the longer run, the production of lactic acid directly from $\mathrm{CO}_{2}$ (e.g., algae or electrochemical conversion) can potentially provide alternatives to current dependence on agriculture feedstocks, thereby reducing the related environmental impacts, including land use.

\section{Comparison with Groot and Borén (2010)}

The results discussed so far build on the previous study from Groot and Borén [8], providing an updated environmental footprint of PLA produced in Thailand from sugarcane at commercial scale, by Total Corbion PLA. Besides the LCI data differences summarized in Table 6, both LCIA studies use different characterization methods that cannot be directly compared, except for $\mathrm{GWP}^{7}$ and land use.

The overall GWP calculated by the two studies $(500 \mathrm{~kg}$ $\mathrm{CO}_{2}$ eq/ton PLA) and the contribution of the different stages remains very similar: the increase in the GWP in sugar production (DLUC and improved mill modelling) is compensated by a lower impact of chemicals and energy (improved efficiency and differences in the Thai grid mix). Land use $\left(\mathrm{m}^{2} /\right.$ ton PLA) is $15 \%$ lower in the current study because of the improved yield of sugarcane crop compared to 2007. Both studies confirm that the largest contributions to land use and PM are in the sugar production phase, while for AP the most relevant process is sulfuric acid production For the remaining impact categories, a comparison cannot be made due to difference in the impact methods and inventory data available.

\section{Data Quality Assessment}

Inventory data quality is judged by its precision, completeness, consistency and representativeness (geographical, temporal, and technological). To cover these requirements and to ensure reliable results, first-hand industry data in combination with background LCI information from Ecoinvent V3.3 allocation default and Agri-footprint V2.0 datasets.

As the majority of the relevant primary data are measured data or calculated based on primary information sources, either measured or calculated, of the owner of the technology (with reference to 2016) precision, completeness and

\footnotetext{
$\overline{7}$ In its assessment Groot and Borén [8] used IPCC 2007 GWP 100a.
} 
Table 7 Evaluation of data quality impact for the most contributing processes based on secondary data

\begin{tabular}{llll}
\hline Dataset & Time coverage & Geographical coverage & Technology coverage \\
\hline Sugarcane cultivation & Yield: 2011-2014 & Thailand and Asian region & Data on related processes \\
Electricity & 2014 & Thailand & Grid mix \\
Heat & Unspecified & RoW dataset adapted to & Similar boiler technology \\
& & Thailand (energy and & \\
& & water) & \\
Chemicals (lime, sulfuric & Unspecified, elec- & RoW dataset adapted to & Technology mix \\
acid and hydrochloric & tricity updated & Thailand (energy and & \\
acid) & $(2014)$ & water) & \\
\hline
\end{tabular}

representativeness is high. No relevant and available data were knowingly omitted. All processes are included, with a cut-off lower than $2 \%$, based on material an energy flows. The data quality assessment of secondary data is summarized in Table 7 . The agricultural emissions to air, soil and water are based on qualified estimations based on models for the same or similar regions.

The methodology was applied consistently to all the components of the analysis. Overall, we consider the quality of the data used sufficient to fulfil the goal and scope of this study.

\section{Conclusions}

This LCA study provides a detailed and updated description (where possible in the view of sensitive information) of the different steps in Total Corbion PLA's production chain for PLA and related environmental impacts, contributing to improve transparency on the communication of environmental impacts of biobased chemicals.

The main impacts of PLA production are related to the agricultural feedstock production and to the manufacturing process of PLA from sugar. The sugarcane crop production has large impacts on most of the environmental impact categories analyzed including GWP, water, eutrophication, acidification and particulate matter and, inevitably, land use. The results of the current study confirm the Groot and Borén [8] study, to the extent that a comparison can be made.

When using biomass to produce PLA and biobased materials, typical concerns are related to land use, including deforestation (land use change) and biodiversity. The 2017 sustainability risk assessment for Corbion's main sugar supplier did not identify significant land transformation to sugar plantations in high carbon stock or high conservation value protected areas. Similarly, the water risk assessment results show low risk for the sourcing areas, where most of the water consumption takes place.

There is significant potential to further reduce the environmental impacts of PLA production. The most significant improvement measures are: (1) increase the sugarcane yield by improved agricultural practices, (2) reduce $\mathrm{NO}_{\mathrm{x}}$ and $\mathrm{SO}_{\mathrm{x}}$ emissions by optimized fertilizer application and (3) increase the electricity exported to the grid by increasing the energy efficiency of the sugar mill and by installing high pressure boilers, (4) increase the use of renewable energy in lactic acid, lactide and PLA production, (5) reduce the use of chemicals in lactic acid production. Combined, these measures have the potential to reduce the $\mathrm{CO}_{2}$ footprint from 501 to $-909 \mathrm{~kg} \mathrm{CO}_{2}$ eq/ton PLA, and further reduce the environmental footprint of PLA.

Acknowledgements The authors want to thank Diana Visser, Richard van Kranenburg, Margit Heine and Kun Chalermkiatkul for their contribution to the different phases of this study, from data collection to modelling and manuscript revision.

Open Access This article is distributed under the terms of the Creative Commons Attribution 4.0 International License (http://creativeco mmons.org/licenses/by/4.0/), which permits unrestricted use, distribution, and reproduction in any medium, provided you give appropriate credit to the original author(s) and the source, provide a link to the Creative Commons license, and indicate if changes were made.

\section{References}

1. European Commission (2017) Growth—sectors: biotechnologybio-based products. http://ec.europa.eu/growth/sectors/biotechnol ogy/bio-based-products_en. Accessed 26 Sept 2018

2. Carus M (2017) Biobased economy and climate change-important links, pitfalls, and opportunities. Ind Biotechnol 13:41-51. https://doi.org/10.1089/ind.2017.29073.mca

3. McGlade C, Ekins P (2015) The geographical distribution of fossil fuels unused when limiting global warming to $2{ }^{\circ} \mathrm{C}$. Nature 517:187

4. European Bioplastics (2017) Bioplastics facts and figures. https ://docs.european-bioplastics.org/publications/EUBP_Facts_and_ figures.pdf. Accessed 26 Sept 2018

5. de Schoenmakere M, Hoogeveen Y, Gillabel, J, Manshoven S (2018) The circular economy and the bioeconomy_partners in sustainability

6. Montazeri Mahdokht, Zaimes George G, Khanna Vikas, Eckelman MJ (2016) Meta-analysis of life cycle energy and greenhouse gas emissions for priority biobased chemicals. ACS Sustain Chem Eng 4:6443-6454. https://doi.org/10.1021/acssuschemeng.6b012 17 
7. Vink ETH, Davies S (2015) Life cycle inventory and impact assessment data for 2014 ingeo $^{\mathrm{TM}}$ polylactide production. Ind Biotechnol 11:167-180. https://doi.org/10.1089/ind.2015.0003

8. Groot WJ, Borén T (2010) Life cycle assessment of the manufacture of lactide and PLA biopolymers from sugarcane in Thailand. Int J Life Cycle Assess 15:970-984. https://doi.org/10.1007/s1136 7-010-0225-y

9. ISO 14040 (2006) Environmental management-life cycle assessment-principles and framework. International Organization for Standardization, Geneva

10. ISO 14044 (2016) Environmental management-life cycle assessment—requirements and guideline. International Organization for Standardization, Geneva

11. Corbion (2017) Environmental footprint of lactic acid and lactide from Thailand, critically reviewed by PRé consultants, Gorinchem (internal document, confidential)

12. Corbion (2017) LCA approach for Corbion's product portfolio: Lactic acid derivative plants, Critically reviewed by PRé consultants. Corbion (internal document, confidential)

13. Vieira M (2017) Exploring the European commission's environmental footprint (PEF/OEF) initiative

14. Sala S, Benini L, Castellani V et al (2016) Environmental Footprint - update of life cycle impact assessment methods; DRAFT for TAB resources, water, land

15. European Commission (EC-JRC-IES) (2011) ILCD recommendations for LCIA in the European context

16. European Commission-Joint Research Centre; Institute for Environment and Sustainability (2010) International reference life cycle data system (ILCD) Handbook-general guide for life cycle assessment-detailed guidance, First edition

17. Manivong P, Bourgois E (2017) White paper: Thai sugarcane sector and sustainability

18. Prado RDM, Caione G, Campos CNS (2013) Filter cake and vinasse as fertilizers contributing to conservation agriculture. Appl Environ Soil Sci. https://doi.org/10.1155/2013/581984

19. Prasara-A J, Gheewala SH (2016) Sustainability of sugarcane cultivation: case study of selected sites in north-eastern Thailand. J Clean Prod 134:613-622. https://doi.org/10.1016/j.jclepro.2015.09.029

20. Yuttitham M, Gheewala SH, Chidthaisong A (2011) Carbon footprint of sugar produced from sugarcane in eastern Thailand. J Clean Prod 19:2119-2127. https://doi.org/10.1016/j.jclepro.2011.07.017

21. Jenjariyakosoln S, Sajjakulnukit B, Garivait S (2013) Energy and greenhouse gas emissions reduction potential of sugarcane field residues power generation in Thailand. Int J Environ Sci Dev 4:182186. https://doi.org/10.7763/IJESD.2013.V4.331

22. Meunchang S, Panichsakpatana S, Weaver RW (2005) Co-composting of filter cake and bagasse; by-products from a sugar mill. Bioresour Technol 96:437-442. https://doi.org/10.1016/j.biort ech.2004.05.024

23. WBCSD (2014) Life cycle metrics for chemical products: a guideline by the chemical sector to assess and report on the environmental footprint of products, based on life cycle assessment

24. Nguyen TLT, Gheewala SH (2008) Fuel ethanol from cane molasses in Thailand: environmental and cost performance. Energy Policy 36:1589-1599. https://doi.org/10.1016/j.enpol.2008.01.008

25. Nguyen TLT (2007) Life-cycle assessment of bio-ethanol as an alternative transportation fuel in Thailand. King Mongkut's University of Technology Thonburi, Thonburi

26. EU (2016) Guidance for the implementation of the EU product environmental footprint (PEF) during the environmental footprint (EF) pilot phase, version 5.2

27. Pawelzik P, Carus M, Hotchkiss J et al (2013) Critical aspects in the life cycle assessment (LCA) of bio-based materials: reviewing methodologies and deriving recommendations. Resour Conserv Recycl 73:211-228. https://doi.org/10.1016/j.resconrec.2013.02.006
28. GRAS, Global Risk Assessment Services (2017) Sustainability risk assessment for one sugar mill in Thailand. Internal confidential report

29. Blonk Consultants (2014) Direct land use change assessment-tool, version 2014.1, Published January 2014. Gouda, Netherlands

30. Gheewala SH, Silalertruksa T, Nilsalab P et al (2014) Water footprint and impact of water consumption for food, feed, fuel crops production in Thailand. Water 6:1698-1718. https://doi.org/10.3390/ w6061698

31. Satyendra T, Singh RN, Shaishav S (2013) Emissions from crop/ biomass residue burning risk to atmospheric quality. Int Res J Earth Sci 1:1-5

32. FAOSTAT (2017) Food and agriculture organization of the United Nations. FAOSTAT. http://www.fao.org/faostat/en/\#country/216

33. Ponsioen TC, van der Werf HMG (2017) Five propositions to harmonize environmental footprints of food and beverages. J Clean Prod 153:457-464. https://doi.org/10.1016/j.jclepro.2017.01.131

34. De Rosa M, Knudsen MT, Hermansen JE (2015) A comparison of land use change models: challenges and future developments. J Clean Prod 113:183-193. https://doi.org/10.1016/j.jclep ro.2015.11.097

35. OECD (2011) Consensus document on compositional considerations for new varieties of sugarcane: key food and feed nutrients

36. Prapaspongsa T, Gheewala SH (2016) Risks of indirect land use impacts and greenhouse gas consequences: an assessment of Thailand's bioethanol policy. J Clean Prod 134:563-573. https://doi. org/10.1016/j.jclepro.2015.05.091

37. Broeren MLM, Zijp M, Waaijers-van der Loop S et al (2017) Environmental assessment of bio-based chemicals in early-stage development: a review of methods. Biofuels, Bioprod Biorefining. https:// doi.org/10.1002/bbb

38. Hoekstra AY, Chapagain AK, Aldaya M, Mekonnen MM (2011) The water footprint assessment manual

39. Sornpoon W, Bonnet S, Kasemsap P et al (2014) Estimation of emissions from sugarcane field burning in thailand using bottomup country-specific activity data. Atmosphere 5:669-685. https:// doi.org/10.3390/atmos5030669

40. ISO 14046 (2014) Environmental management. Water footprintprinciples, requirements and guidelines

41. Boulay A-M et al (2016) Water use related impacts: water scarcity and human health effects - part 1: water scarcity. Rolf Frischknecht and Olivier Jolliet. Global Guidance for Life Cycle Impact Assessment Indicators, vol 1(s.l). UNEP/SETAC Life Cycle Initiative, pp $101-124$

42. World Resources Institute (WRI) (2015) Aqueduct global maps 2.1: water risk atlas. http://www.wri.org/applications/maps/ aqueduct-atlas/\#x=-123.31\&y=-14.51\&s=ws!20!28!c \&t=water risk \& $\mathrm{w}=$ def $\& \mathrm{~g}=0 \& \mathrm{i}=\mathrm{BWS}-16$ ! WSV-4!SV-2!HFO-4!DRO4!STOR-8!GW-8!WRI-4!ECOS-2 !MC-4!WCG-8!ECOV2 ! \& tr $=$ ind -1 ! prj- $1 \& l=3 \& b=$ terrain $\& m=$ single-BWS

43. Goedkoop M et al (2009) ReCiPe 2008: a life cycle impact assessment method which comprises harmonised category indicators at the midpoint and the endpoint level, Report I38. IEA, International

44. Bonsucro (2018) http://bonsucro.com/

45. BONSUCRO (2016) Guidance for the production standard-including guidance for the Bonsucro EU production Standard Version 4.2

46. Kamate SC, Gangavati PB (2009) Cogeneration in sugar industries: technology options and performance parameters - a review. Cogener Distrib Gener J 24:6-33. https://doi.org/10.1080/154536609095951 48

47. Waclawovsky AJ, Sato PM, Lembke CG et al (2010) Sugarcane for bioenergy production: an assessment of yield and regulation of sucrose content. Plant Biotechnol J 8:263-276. https://doi.org/10.1 $111 / j .1467-7652.2009 .00491 . x$ 
48. Groot Wim et al (2010) Production and purification of lactide. Poly(lactic acid): synthesis, structures, properties, processing, and applications. Wiley, Hoboken, pp 3-18

49. Carus M, Dammer L (2013) Food or non-food: which agricultural feedstocks are best for industrial uses? Ind Biotechnol 9:171-176. https://doi.org/10.1089/ind.2013.1580

50. Dones R, Bauer C, Bolliger R, Burger B, Faist Emmenegger M, Frischknecht R, Heck T, Jungbluth N, Röder A, Tuchschmid M (2007) Life cycle inventories of energy systems: results for current systems in Switzerland and other UCTE countries. Ecoinvent report no. 5. Paul Scherrer Institut Villigen, Swiss Centre for Life Cycle Inventories, Dübendorf, $\mathrm{CH}$

Publisher's Note Springer Nature remains neutral with regard to jurisdictional claims in published maps and institutional affiliations. 